\title{
FIRST INTERNATIONAL CONFERENCE ON FEVER THERAPY
}

THE first international meeting on fever therapy will be held in New York City, September, I936. The use of fever induced by physical and other agencies as a therapeutic procedure has received universal attention in the past few years. The conference will aim to collect and crystallise available data in this field. Therapeutic, physiological and pathological phases of fever will be discussed.

The suggestion for this conference originated with a group of interested European physicians. Five national conferences have been held in the United States of America. The first three sessions met at Rochester University Medical School in I93I, I932 and I933. The fourth assembled at Columbia University College of Physicians and Surgeons in 1934. The fifth was held in I935 at Miami Valley Hospital, Dayton, Ohio.

It is planned to translate abstracts of all the papers into French, English and German. In order to make the printed copies of the transactions available for the conference, it is necessary that manuscripts and abstracts be sent in not later than June Ist, I936. Those interested in participating are requested to make early application.

Further information concerning the conference may be obtained from the Secretary.

Baron Henri de Rothschild, Chairman, PARIS, France.

Dr. William Bierman, Secretary, 47I Park Avenue,

New York City, U.S.A.

American Committee :

Dr. A. U. Desjardins, Chairman.

Dr. W. Bierman.

Dr. F. W. Hartman.

DR. L. E. Hinsie.

DR. C. A. Neymann.

DR. W. M. Simpson.

Dr. S. L. WARren. 